\title{
Intraosseous lipomas originating from simple bone cysts
}

\author{
Jacques Malghem ${ }^{1} \cdot$ Frederic Lecouvet $^{1} \cdot$ Patrick Omoumi $^{2} \cdot$ Bruno Vande Berg $^{1}$
}

Received: 10 May 2021 / Revised: 10 May 2021 / Accepted: 27 May 2021 / Published online: 8 June 2021

(c) ISS 2021

We read with great interest the paper entitled "Intraosseous lipomas originating from simple bone cysts," recently published by Tins et al. in Skeletal Radiology [1], in which the authors describe six cases of simple bone cysts (SBCs) demonstrating filling in of the cystic content with fat from the periphery at follow-up. The authors therefore conclude that at least part of the so-called intraosseous lipomas are healed SBCs.

While we completely agree with this conclusion, we are surprised that the authors write that the cases they described are the first definitive proof that at least some (and possibly all) SBCs heal to assume the imaging characteristics of intraosseous lipoma. In fact, in a paper published in Skeletal Radiology in 2017, we had already reported a presumed calcaneal bone cyst evolving at follow-up imaging towards a calcaneal lipoma [2]. A similar case was published later by Powell et al. [3].

Of note, all cases reported by Tins et al. had undergone either curettage or needle biopsy, and therefore do not correspond to a spontaneous evolution of SBCs. Fat replacement of a humeral SBC after treatment by intracavitary injections of corticosteroid and ethanol was also previously demonstrated by Wada and Lambert using MRI and CT [4].

Our case was the first report of a bone cyst spontaneously evolving to assume the aspect of an intraosseous lipoma, without any external intervention. This example of fatty involution after spontaneous healing of a bone cyst can account for the rare but non-exceptional observation of the so-called intraosseous lipomas in the os calcis or elsewhere, which could correspond to old bone cysts.

As a matter of fact, fatty involution could be a nonspecific phenomenon indicating lesion healing, as observed after treatment in some neoplastic or inflammatory bone marrow lesions [5, 6]. In French, we sometimes use a pun to describe the fatty replacement of bone marrow lesions that regress: une lésion "re-graissante" est une lésion régressante (of which an approximate translation would be $a$ "regreasing" lesion is a regressing lesion).

Authors' Contributions 1) All authors make substantial contributions to conception and design, and/or acquisition of data, and/or analysis and interpretation of data;

2) All authors participate in drafting the article or revising it critically for important intellectual content; and

3) All authors give final approval of the version to be submitted and any revised version.

\section{References}

1. Tins BJ, Berkowitz YJ, Konala P, et al. Intraosseous lipomas originating from simple bone cysts. Skeletal Radiol. 2021;50:801-6.

2. Malghem J, Lecouvet F, Vande BB. Calcaneal cysts and lipomas: a common pathogenesis. Skeletal Radiol. 2017;46:1635-42.

3. Powell GM, Turner NS, Broski SM, Ringler MD, Howe BM. Intraosseous "lipoma" of the calcaneus developing in an intraosseous ganglion cyst. J Radiol Case Rep. 2018;12:16-24.

4. Wada R, Lambert RGW. Deposition of intraosseous fat in a degenerating simple bone cyst. Skeletal Radiol. 2005;34:415-8.

5. Lecouvet FE, Larbi A, Pasoglou V, et al. MRI for response assessment in metastatic bone disease. Eur Radiol. 2013;23:1986-97.

6. Malghem J, Vande Berg B, Lecouvet F, Koutaissoff S. Maldague $\mathrm{B}$ [Principles of analysis for sacroiliac joints imaging]. JBR-BTR. 2007;90:358-67.

Publisher's Note Springer Nature remains neutral with regard to jurisdictional claims in published maps and institutional affiliations.

Jacques Malghem

jacques.malghem@uclouvain.be

1 Département de Radiologie et Imagerie Médicale,

UCLouvain, Brussels, Belgium

2 Service de Radiodiagnostic et Radiologie Interventionnelle, Lausanne University Hospital, Lausanne, Switzerland 